\title{
Adult attachment insecurity and dyadic adjustment: The mediating role of self-criticism
}

\author{
Teresa C. Martins ${ }^{1,2}$, Maria Cristina Canavarro ${ }^{1} \&$ Helena Moreira $^{1}$ \\ ${ }^{1}$ Cognitive-Behavioral Research Centre (CINEICC), Faculty of Psychology and Education \\ Sciences, University of Coimbra, Coimbra, Portugal \\ ${ }^{2}$ Centre for Neurosciences and Cell Biology (CNC), University of Coimbra, Coimbra, \\ Portugal
}

Sources of financial assistance: This work was partially supported by the Portuguese Foundation for Science and Technology [SFRH/BPD/70063/2010].

Conflicts of interest: none

\section{Corresponding author:}

Teresa C. Martins

Medical Physics Service

Portuguese Institute for Oncology at Coimbra,

Av. Bissaya Barreto 98

3001-651 Coimbra, Portugal.

Telephone: 00351239400200

E-mail: tcmartins@netcabo.pt

Short title: Attachment, self-criticism and dyadic adjustment 


\begin{abstract}
Objectives: Although it is well established that adult attachment is associated with relationship quality, the mechanisms involved in this association are still poorly understood. Individual variables that are shaped in early attachment experiences, such as self-criticism, may be particularly important. The present study aimed to investigate the mediating role of self-criticism and self-reassurance on the association between attachmentrelated anxiety and avoidance and dyadic adjustment. Design and Methods: 230 individuals from a community sample completed an online battery of self-report measures of adult attachment, dyadic adjustment, and forms of self-criticism and self-reassuring. A parallel mediation model was tested. Results: Data showed that attachment anxiety and avoidance were associated with poorer dyadic adjustment through high levels of selfcriticism in the form of an inadequate self. Conclusions: Our findings highlight the importance of targeting feelings of self-inadequacy in couple therapy to promote better dyadic adjustment and relationship functioning. The innovative contribution of this work is the identification of a new mechanism underlying the association between adult attachment and dyadic functioning.
\end{abstract}

Keywords: attachment, dyadic adjustment, self-criticism, inadequate self

\title{
Practitioner points:
}

- Self-criticism in the form of an inadequate self mediates the association between attachment and dyadic adjustment 
- Although correlated with attachment dimensions and dyadic adjustment, the hated self and the reassured self do not act as mediators of the relationship between attachment and dyadic adjustment

- It seems important to evaluate and address feelings of inadequacy in the context of couple therapy 


\section{Introduction}

Attachment theory has been used as the major conceptual framework for the study of romantic relationships (Hazan \& Shaver, 1987; Mikulincer \& Goodman, 2006). Attachment security is associated with greater satisfaction and more trustful experiences in romantic relationships (McCarthy \& Maughan, 2010; Meyers \& Landsberger, 2002; Saavedra, Chapman, \& Rogge, 2010), while attachment insecurity negatively correlates with the quality of couple relationships (e.g., Lopez, Riggs, Pollard, \& Hook, 2011). However, the mechanisms explaining the association between attachment (in)security and dyadic functioning are still poorly understood, particularly with regard to individual variables that originate in early attachment relationships. In this study, we focus on self-criticism, which arises from early experiences with primary caregivers and may impact intimate relationship functioning.

\section{Self-criticism and Attachment (In)security}

Self-criticism is a form of self-relating that involves constant, harsh self-evaluation as well as a chronic fear of others' criticism, disapproval and rejection (Blatt \& Homann, 1992). It can be understood from the perspective of social mentalities theory (Gilbert, 2000), according to which humans develop modes of functioning (e.g., cooperative, social

rank) that influence the emergence of interpersonal schemata and guide people to create certain types of roles with others. Social mentalities affect the interpretation of the social roles of others with regard to the self and their affective and behavioural responses. In this context, self-criticism is viewed as related to social rank mentality (Gilbert, Baldwin, Irons, Baccus, \& Palmer, 2006). In this internal attack-submission relationship, activated in times 
of failure, there is a part of the self that identifies self-flaws, makes accusations, condemns and hates the self, and a part of the self that submits (Castilho, Pinto-Gouveia, \& Duarte, 2013; Sturman \& Mongrain, 2008).

Self-criticism has its origins in interpersonal schemata developed in negative developmental experiences, particularly regarding parenting and early attachment experiences (Baldwin, 1992, 2005; Kopala-Sibley \& Zuroff, 2014). The critical influence of attachment relationships in human development is one of the tenets of attachment theory (Bowlby, 1982/1969, 1973), which sustains that, based on the infant's expectations regarding the accessibility and responsiveness of the caregiver, individuals develop broader representations (internal working models, IWM) of the self (e.g., self-concept and selfreferential beliefs) and the attachment figures, as well as interpretations of the individual relational experiences and rules about how to interact with other people (Gillath, Shaver, \& Mikulincer, 2005; Thompson, 2008). When an attachment figure is consistently responsive and acts as a soothing agent, the child develops a sense of security and becomes able to cope with setbacks using self-warmth and -reassurance (Gilbert \& Procter, 2006; Mikulincer \& Shaver, 2004). In contrast, if an attachment figure is unresponsive, neglectful or abusive, security is not attained and the child develops secondary affect regulation strategies, characterised by anxiety or avoidance (Gillath et al., 2005). These children may learn to see significant others as threatening and more powerful and may become focused on social rank, using self-criticism as a survival tool to deal with the inconsistent care or unresponsiveness of caregivers because blaming more powerful others is perceived as risky (Cantazaro \& Wei, 2010; Gilbert \& Irons, 2004; Gilbert \& Procter, 2006).

Self-criticism positively correlates with insecure attachment and negative relational 
schemata (Blatt \& Homann, 1992; Irons, Gilbert et al., 2006; Kopala-Sibley, Zuroff, Levbam, \& Hope, 2013; Thompson \& Zuroff, 1999; Zuroff \& Duncan, 1999). In turn, secure attachment negatively correlates with self-criticism and positively correlates with self-reassurance (Irons et al., 2006; Kopala-Sibley et al., 2013). Cantazaro and Wei (2010) proposed that people high in attachment anxiety, who have a negative IWM of the self, can automatically engage in self-criticism and striving for others' acceptance, with the motivation for self-correction and improvement, which reduce the chances of being criticised or disapproved of, and increase the probability of gaining others' approval and admiration. This insecure, perfectionist striving is theorised to be used also by individuals high in self-criticism and attachment avoidance, who have a negative IWM of others and have developed beliefs regarding the need to be highly competent or nearly perfect to maintain self-reliance and avoid rejection.

\section{Self-criticism and Romantic Relationships}

Self-criticism is often associated with ambivalence in romantic relationships. People high in self-criticism desire approval, respect and admiration, and fear losing the love of their partners, while also fearing dependency, closeness and loss of control and autonomy (Lowyck, Luyten, Demyttenaere, \& Croveleyn, 2008; Zuroff \& Fitzpatrick, 1995). They tend to neglect interpersonal relationships in their pursuit of achievement and self-esteem, do not strive for intimacy and have low internal motivation to establish intimate relationships, valuing relationships only as a way to define identity and increase self-esteem (Blatt, 2004; Santor \& Zuroff, 1998; Zuroff \& Fitzpatrick, 1995). Due to their feelings of inadequacy, they frequently engage in positive self-presentation strategies (e.g., to make a 
positive impression on others), are often reluctant to self-disclose and may use selfsilencing as a defensive strategy to maintain or improve their relationships. However, these behaviours may impede intimacy (Besser, Flett, \& Davis, 2003; Lowyck et al., 2008; Zuroff \& Fritzpatrick, 1995). Individuals high in self-criticism tend to remain distrustful and dissatisfied in intimate relationships (Zuroff \& Fitzpatrick, 1995), often describing their romantic partners as less loving and more controlling (Amitay, Mongrain, \& Fazaa, 2008).

To compensate for their perceived inadequacy, and because of their evaluative and perfectionist concerns, self-critical individuals tend to act competitively in relationships, control resources, fail to attend to differences in behaviour and status, and criticise and blame their partners. These actions may lead to confrontations and misunderstandings between romantic partners, rejection, a sense of relational failure, worthlessness and increased self-criticism (Santor, Pringle, \& Israeli, 2000; Shahar, Joiner, Zuroff, \& Blatt, 2004; Santor \& Zuroff, 1998; Zuroff \& Fitzpatrick, 1995). These situations of increased interpersonal stress are further amplified by the negative cognitive-affective reactivity of self-critical individuals (e.g., increased hostility) and their inability to generate protective

social factors and positive events (Shahar et al., 2004; Zuroff \& Duncan, 1999; Zuroff \& Mongrain, 1987).

\section{The Current Study}

Given the relationship between attachment, self-criticism and interpersonal functioning, this study aimed to investigate whether self-criticism mediated the association between attachment dimensions and dyadic adjustment, since, to the best of our knowledge, this mechanism has never been investigated. Previous studies have shown that self- 
criticism mediates the association between childhood emotional maltreatment and impairment in romantic relationships (Lassri \& Shahar, 2012) and between attachment and loneliness (Wiseman, Mayseless, \& Sharabany, 2006). Understanding the role of selfcriticism may be important for the identification of new therapeutic targets that are more manageable than interpersonal schemata or attachment patterns.

In this work, different forms of self-criticism and reassurance were evaluated: (1) inadequate self, focused on disappointment, inferiority and feelings of inadequacy; (2) hated self, focused on self-disgust and -hatred; and (3) reassured self, which negatively correlates to the other two and refers to self-support or -compassion (Gilbert, Clarke, Hempel, Miles, \& Irons, 2004). It was expected that: (1) higher levels of attachment anxiety and avoidance would be associated with increased self-criticism (inadequate and hated self) and decreased self-reassurance, which, in turn, would relate to poorer dyadic adjustment; and 2) attachment avoidance would more strongly negatively correlate with selfreassurance than attachment anxiety. These hypotheses were based in studies showing the effects of early attachment experiences in the development of self-criticism. These experiences lead to development of IWM of the self and others that are directly associated with the individual's capacity to create and maintain successful close relationships, establish a positive self-concept and develop constructive social representations of people and relationships (Cassidy, 1988; Doyle, Markiewicz, Brendgen, Lieberman, \& Voss, 2000). Secure attachment experiences also teach individuals to self-reassure when things go wrong (Mikulincer \& Shaver, 2004; Weinfield, Sroufe, Egeleand, \& Carlson, 2008). In contrast, insecurely attached individuals grow to see the self as not deserving a better treatment, because the self is essentially "bad" (Weinfield et al., 2008). Insecure attachment 
experiences may contribute to feelings of self-inadequacy and -hatred. Attachment anxiety and avoidance result from distinct relational experiences and lead to development of different affect regulation strategies (Gillath et al., 2005). Anxiously attached people experience inconsistent care from attachment figures and use hyperactivating strategies to elicit care from others. Thus, they may have had soothing experiences with the caregivers and have some access (though limited and ineffective) to the soothing system of emotion regulation. In contrast, early attachment experiences of avoidant individuals are characterized by consistent irresponsiveness, leading to adoption of deactivation strategies and avoidance of negative emotions (Gillath et al., 2005). Lack of soothing experiences with the attachment figures may impede access to the soothing system. Finally, selfcriticism has been shown to negatively affect romantic relationships (e.g., Lowyck et al., 2008; Zuroff \& Fitzpatrick, 1995), whereas self-compassion and -reassurance associate with a more positive behaviour in romantic relationships (Neff \& Beretvas, 2012).

\section{Methodology}

\section{Participants}

The sample comprised 230 Caucasian subjects from the general population who met the following inclusion criteria: (a) 18 years old or older; and (b) in a romantic relationship for at least six months. The socio-demographic characteristics of the sample are presented in Table 1.

$$
\text { [Table_1_should_go_here] }
$$

\section{Procedure}

A battery of self-report questionnaires was provided to the participants online, 
accompanied by an introductory text that presented the inclusion criteria and information on confidentiality and ethical issues. Only those who agreed with these conditions filled out the questionnaire. An invitation for participation was distributed through an email containing a brief explanation of the study and the survey link, which was sent to different departments of the University of Coimbra (researchers, staff and graduate students) and to the researchers' acquaintances, friends and family. Additionally, all potential participants were asked to forward the email to at least one person to obtain the largest and most diverse community sample possible. Participation in the study was voluntary. No compensation was given to the participants.

\section{Measures}

Adult attachment. The Portuguese version of the Experiences in Close Relationships - Relationship Structures (ECR-RS) scale (Fraley, Heffernan, Vicary, \& Brumbaugh, 2011; Moreira, Martins, Gouveia, \& Canavarro, 2014) was used to measure attachment anxiety (3 items; e.g. "I often worry that my partner doesn't really love me") and avoidance (6 items; e.g. "I don't feel comfortable opening up to romantic partners") in different types of close relationships (mother, father, romantic partner and best friend). Global measures of attachment anxiety and avoidance can be obtained through the estimation of the means of the two dimensions in the four targets. For each target, the scale is composed of nine items rated on a seven-point Likert scale ranging from 1 (Strongly disagree) to 7 (Strongly agree). Higher scores on these subscales are indicative of high attachment avoidance and anxiety. In this study, we used the global anxiety and avoidance scores.

Fraley et al. (2011) found the ECR-RS to be a psychometrically sound measure of the 
two dimensions in the four relational domains and provided evidence of its reliability (Cronbach's $\alpha$ ranged from .85 to .92 ) and validity. The Portuguese version revealed adequate reliability (Cronbach's $\alpha$ ranged from .72 to .91 ) and confirmed the original twofactor structure. In the present study, Cronbach's $\alpha$ was .88 for the Avoidance Subscale and .93 for the Anxiety Subscale.

Forms of self-criticism. The Portuguese version of the Forms of SelfCriticising/Attacking and Self-Reassuring Scale (FSCRS; Castilho et al., 2013; Gilbert et al., 2004) was used to evaluate the way people think about themselves when things go wrong. This scale is composed of 22 items rated on a five-point Likert scale ranging from 0 (Not at all like me) to 4 (Extremely like me). The scale is composed of three factors: Inadequate Self (e.g., "I remember and dwell on my failings"), Hated Self (e.g., "I do not like being me"), and Reassured Self (e.g., "I can still feel lovable and acceptable"). Gilbert et al. (2004) reported good reliability for FSCRS, with Cronbach's $\alpha$ coefficients of .86 for hated and reassured self, and .90 for inadequate self. The Portuguese version confirmed the three-factor structure in clinical and nonclinical samples, also demonstrating adequate internal consistency (Cronbach's $\alpha$ ranged from .72 to .89 in a nonclinical sample and from .81 to .91 in a clinical sample). In the current study, the Cronbach's $\alpha$ for Inadequate Self was .88, for Hated Self was .69, and for Reassured Self was .87.

Dyadic adjustment. The Portuguese version of Revised Dyadic Adjustment Scale (RDAS; Busby, Christensen, Crane, \& Larson, 1995; blind for review, 2014) was used to 
measure the individual's perceived dyadic functioning. This self-report questionnaire, consisting of 14 items rated on five- or six-point Likert scales, measures the adjustment in romantic relationships with regard to consensus (decision making, values and affection), satisfaction (stability and conflict), and cohesion (activities and discussions). The RDAS has shown adequate reliability, construct validity and criterion validity (Busby et al., 1995). In this study, the Cronbach's $\alpha$ of the scale was .82 .

\section{Data Analysis}

The data analyses were conducted using the Statistical Package for the Social Sciences (SPSS, version 20.0; IBM SPSS, Chicago, IL). Missing values were handled through the SPSS Missing Values Analysis (MVA). Only Attachment Avoidance and Reassured Self had more than $5 \%$ of missing values ( $7.8 \%$ and $6.5 \%$, respectively). Little's MCAR test was conducted to test whether the data were missing completely at random (MCAR). A non-significant result was obtained, $\chi^{2}(64)=80.89, p=.075$, indicating that MCAR may be inferred (Tabachnick \& Fidell, 2007). Separate $t$-tests showed no systematic relationship between missingness on Attachment Avoidance, Reassured Self and the other variables. The only exception was the difference between cases with missing and nonmissing values on Attachment Avoidance on Hated Self, $t(28,1)=3.0, p=.005$, with individuals with missing information reporting higher levels of Hated Self. The expectation maximization imputation approach was used for estimating missing values.

Descriptive statistics were computed for all socio-demographic and study variables. Correlations between socio-demographic and study variables were performed to identify 
possible covariates. Cohen's guidelines (1988) were used to describe the effect sizes of correlations (i.e., small for correlations close to .10, medium for those near .30 , and large for correlations of .50 or higher).

Mediation models were tested with PROCESS (Hayes, 2013), a SPSS macro for path analysis-based moderation and mediation analysis. A parallel multiple mediation model ("model 4" in Hayes, 2013) with three mediators was estimated. Prior to estimation, all variables were standardized. A bootstrapping procedure using 10000 resamples was used to assess unconditional indirect effects. Bootstrapping is a nonparametric resampling procedure that is recommended for testing indirect effects because it does not require the assumption of normality of the sampling distribution of the indirect effects (Hayes, 2013). This procedure creates $95 \%$ bias-corrected and accelerated confidence intervals (BCaCIs) of the indirect effects. An indirect effect is considered significantly different from zero if zero is not contained within the lower and upper CIs. The empirical power tables proposed by Fritz and MacKinnon (2007) for mediation models suggest that the sample size of this study is sufficient to find a mediated effect including small-to-medium $\alpha$ and $\beta$ paths ( $\alpha$ and $\beta=.26)$ with a .80 power.

\section{Results}

\section{Descriptive Statistics and Correlations}

The means, standard deviations, and intercorrelations for the study variables are

presented in Table 2. Attachment avoidance and anxiety were both negatively and moderately correlated with dyadic adjustment $(r=-.27, p<.001$, for both). There was a 
medium and positive correlation between attachment dimensions and hated (attachment avoidance: $r=.34, p<.001$; attachment anxiety: $r=.36, p<.001)$ and inadequate self $(r=.29$, $p<.001$, for both); a medium to high, negative correlation between attachment avoidance and reassured self $(r=-.46, p<.001)$; and a moderate, negative correlation between attachment anxiety and reassured self $(r=-.25, p<.001)$. Self-criticism was moderately and negatively correlated with dyadic adjustment (inadequate self: $r=-.38, p<.001$; hated self: $r=-.27, p<.001$ ), whereas self-reassurance was moderately and positively correlated with dyadic adjustment $(r=.29, p<.001)$.

Intercorrelations between socio-demographic and study variables were also analysed. Significant correlations were found between attachment avoidance and age $(r=.25, p<.001)$, relationship duration $(r=.18, p=.007)$ and cohabiting time $(r=.18, p=.007)$; between attachment anxiety and age $(r=.21, p=.001)$, relationship duration $(r=.14, p=.037)$ and cohabiting time ( $r=.13, p=.050)$; between inadequate self and relationship duration $(r=-.13$, $p=.049)$; and between reassured self and age $(r=-.16, p=.013)$, relationship duration ( $r=-$ $.13, p=.048)$ and cohabiting time $(r=-.13, p=.046)$.

[Table_2_should_go_here]

\section{Mediation Analysis}

To evaluate the indirect effect of attachment dimensions on dyadic adjustment through self-criticism and -reassurance, a parallel multiple mediation model was estimated. In this model, dyadic adjustment acted as the dependent variable (DV); attachment dimensions as the independent variables (IV); and inadequate, hated, and reassured selves 
as the mediators $\left(\mathrm{M}_{1}, \mathrm{M}_{2}\right.$, and $\left.\mathrm{M}_{3}\right)$. The effects of the IV on the proposed Ms (paths $a_{1}, a_{2}$, and $a_{3}$ ), the effects of $\mathrm{M}_{1}, \mathrm{M}_{2}$, and $\mathrm{M}_{3}$ on the DV partialling out the effect of IV and the other $\mathrm{M}$ variables (paths $b_{1}, b_{2}$, and $b_{3}$ ), the direct effect of IV on DV after controlling for $\mathrm{M}_{1}, \mathrm{M}_{2}$, and $\mathrm{M}_{3}$ (path $c^{\prime}$ ), and the total effect of IV on DV (path $c$ ) are presented in Figure 1. Age and relationship duration were entered as covariates. Cohabiting time was not included in the model as a covariate due to its high correlation with relationship time $(r=.94)$.

The analysis of individual paths showed that attachment anxiety and avoidance were significantly associated with inadequate self $(b=.23, S E=.07, p<.001 ; b=.25, S E=.07$, $p<.001$, respectively), explaining $16.4 \%$ of its variance $\left(R^{2}=.164, F(4,224)=11.03, p<.001\right)$; and with hated self $(b=.27, S E=.07, p<.001 ; b=.25, S E=.07, p<.001$, respectively), explaining $20.1 \%$ of its variance $\left(R^{2}=.210, F(4,225)=14.12, p<.001\right)$. Reassured self was significantly associated with attachment avoidance $(b=-.42, S E=.07, p<.001)$, but not with attachment anxiety $(b=-.08, S E=.06, p=.21)$, with attachment dimensions explaining $22 \%$ of its variance $\left(R^{2}=.220, F(4,225)=15.88,<.001\right)$.

Dyadic adjustment was significantly associated with inadequate self $(b=-.30, S E=.08$, $p<.001)$, but not with hated $(b=.04, S E=.09, p=.62)$ or reassured self $(b=.09, S E=.08$, $p=.27)$. The direct effects of attachment avoidance and anxiety on dyadic adjustment were not significant $(b=-.11, S E=.07, p=.14 ; b=-.13, S E=.07, p=.06$, respectively). All the variables explained $19.1 \%$ of the dyadic adjustment variance $\left(R^{2}=.191, F(7,222)=7.50\right.$, $p<.001)$.

Significant specific indirect effects of attachment dimensions on dyadic adjustment through inadequate self were found $\left(a_{1} b_{1}=-.069, S E=.03,95 \% \mathrm{BCaCI}[-.14,-.02] ; a_{1} b_{1}=-\right.$ 
$.074, S E=.03,95 \% \mathrm{BCaCI}[-.15,-.03])$, meaning that people with increased attachment anxiety and avoidance have poorer dyadic adjustment as a result of increased self-criticism in the form of inadequate self. Conversely, the indirect effects of attachment dimensions on dyadic adjustment were not significant through hated $\left(a_{2} b_{2}=.012, S E=.03,95 \% \mathrm{BCaCI}[-.04\right.$, $\left..09] ; a_{2} b_{2}=.010, S E=.03,95 \% \mathrm{BCaCI}[-.04, .07]\right)$ or reassured self $\left(a_{3} b_{3}=-.01, S E=.01\right.$, 95\%BCaCI $\left.[-.05, .01] ; a_{3} b_{3}=-.036, S E=.04,95 \% \mathrm{BCaCI}[-.13, .04]\right)$.

[Figure_1_should_go_here]

\section{Possibility of alternative models}

Given the cross-sectional nature of this study, alternative models may exist. According to Blatt's two polarities model (Luyten \& Blatt, 2011), after the development of self-criticism as a consequence of early experiences with significant others, its levels may be altered by later experiences in close relationships. To analyse this possibility, we tested three models in which dyadic adjustment mediated the association between attachment dimensions and different forms of self-criticism. We have followed the same procedures as described for the proposed mediation model. The results supported these models (Table 3). Higher levels of attachment anxiety and avoidance were associated with worse dyadic adjustment ( $b=-.19, S E=.07, p=.005 ; b=-.21, S E=.07, p=.003$, respectively), explaining $10.58 \%$ of dyadic adjustment variance. Dyadic adjustment was associated with increased levels of self-criticism (inadequate self: $b=-.29, S E=.06, p<.001$; hated self: $b=-.15, S E=.06$, $p=.02)$ and lower levels of self-reassurance $(b=.17, S E=.06, p=.006)$. All the variables explained $24 \%$ of inadequate self $\left(R^{2}=.240, F(5,224)=14.12, p<.001\right), 22 \%$ of hated self 
$\left(R^{2}=.220, F(5,224)=12.64, p<.001\right)$ and $25 \%$ of reassured self $\left(R^{2}=.246, F(5,224)=14.59\right.$, $p<.001)$.

\section{Discussion}

This study explored the mediating role of self-criticism and self-reassurance on the links between attachment dimensions and dyadic adjustment. The main and innovative finding was the mediator role of inadequate self. Our results did not confirm the hypothesis of a mediator role for hated or reassured self, when controlling for the other mediators, despite the significant association of these variables with attachment dimensions and dyadic adjustment. The absence of a mediating role for hated self may result from the fact that normative samples usually present low levels of this form of self-criticism in contrast to clinical samples. In addition, the effects of inadequate self may have masked those of hated self, due to their high intercorrelation. This may also hold true for reassured self.

Although a significant correlation was found between attachment dimensions and dyadic adjustment, the direct effect of attachment on dyadic adjustment was nonsignificant, suggesting that this relationship may be better explained by self-criticism facets. Our data suggest that the mediating effect of self-criticism is due to the development of a poor sense of self in insecure early attachment experiences. People high in attachment anxiety develop a negative IWM of the self and feel inadequate, using self-criticism as a motivation for self-correction and improvement while striving for others' love and acceptance (Cantazaro \& Wei, 2010). Although it is usually posited that attachment avoidance is mainly related to a negative IWM of others, the positive association between attachment avoidance and feelings of inadequacy suggests that avoidant individuals 
(possibly fearful avoidant individuals) also have a negative view of the self. It is possible that individuals high in attachment avoidance perceive others as rejecting because they evaluate themselves negatively and feel inadequate. Their withdrawal from others may constitute a defensive, self-protective strategy to hide an underlying negative sense of self (Gross \& Hansen, 2000). Avoidantly attached individuals tend to exhibit a defensive organization of the self, characterized by poor access to negative self-attributes, weak integration of these attributes with other self-related features and use of defensive strategies (e.g., self-inflation), which results from fear of rejection and is used to maintain a consistent self-concept (Cassidy, 1988; Mikulincer, 1995; Mikulincer \& Shaver, 2008; Smolewska \& Dion, 2005).

As expected, there was a stronger negative correlation of reassured self with attachment avoidance than with attachment anxiety. Highly avoidant individuals may have had attachment experiences with irresponsive non-soothing caregivers (Gillath et al., 2005; Mikulincer \& Shaver, 2004). Consequently, they may never have experienced soothing, learned to self-reassure or access the soothing system. In contrast, although limited, anxiously attached people may still have had early soothing experiences, which may facilitate activation of the soothing system.

The negative association between inadequate self and dyadic adjustment may be explained in several ways, namely through fear of intimacy. Because people high in selfcriticism believe that they will be disapproved of or rejected if they reveal their true, inadequate selves, may be pessimistic about others' acceptance, and may have difficulty believing that they are loved (Murray, Holmes, Griffin, Bellavia, \& Rose, 2001; Overall \& Fletcher, 2010), they are reluctant to self-disclose, may engage in positive self-presentation 
or self-silencing strategies (Blatt, 2004; Besser et al., 2003; Lowyck et al., 2008; Santor \& Zuroff, 1998; Zuroff \& Fritzpatrick, 1995), and may protect themselves from expected rejection by devaluing and withdrawing from their partners (Murray, Bellavia, Rose, \& Griffin, 2003; Zuroff \& Fitzpatrick, 1995). This may negatively affect relationship quality because positive self-disclosure increases the partner's perceived regard and acceptance (Laurenceau, Feldman, Barrett, \& Pietromonaco, 1998).

Another explanation relates to the high competitiveness and perfectionist strivings of individuals high in self-criticism within relationships and increased concerns with social comparison, which may lead to interpersonal tension and conflict (Gilbert, McEwan, Bellew, Mills, \& Gale, 2009; Shahar et al., 2004), excessive reactions to perceived failures, and feelings of loss of love, trust and respect from the partner. Far from achieving a sense of security, these individuals may be overwhelmed by a sense of relational failure, further increasing their self-criticism and feelings of inadequacy. They may alternatively adopt a submissive posture towards their partners, which can lead to lack of control over relationship outcomes and to rejection, confirming judgments of one's inferiority and the need to be submissive (Gilbert, 2000). Additionally, partners may be perceived as demanding unattainable standards in exchange for their love, which may trigger anger and hostility in self-critical individuals, resulting in highly hostile, critical and rejecting dyadic conflict (Lawrence, Eldridge, \& Christensen, 1998; Mackinnon, Sherry, Antony, Stewart, Sherry, \& Hartling, 2012). This negative regulation of the romantic partner conveys a message of contempt and disregard for the feelings and desires of the target and results in reduced inferred ideal consistency and more negative evaluations of relationship quality (Overall \& Fletcher, 2010). Further research is needed to address these hypotheses. 
Alternative models may exist. We have observed that attachment dimensions may be associated with self-criticism and -reassurance through dyadic adjustment, an observation that is in agreement with Blatt's model. Nevertheless, the observation that, in the originally proposed model, the association between attachment dimensions and dyadic adjustment is exclusively mediated by inadequate self strengthens the relevance of this model.

Interestingly, we observed that attachment anxiety and avoidance increased with age. Age differences in attachment dimensions are consistent with the possibility of revision of existing attachment orientations based on new information and life experiences (Chopik, Edelstein \& Fraley, 2013). However, the few available studies have yielded conflicting results (e.g., Chopik et al., 2013; Magai, 2008; Magai, Hunziker, Mesias, \& Culver, 2000; Zhang \& Labouvie-Vief, 2004). Intimate relationships are thought to promote attachment security only if people feel comfortable and confident within the relationship and if spouses fulfil attachment functions and needs (Davilla, Karney, \& Bradbury, 1999). Thus, the herein described age differences in attachment orientations may result from relationship quality and interpersonal behaviour. They may also result from cohort effects (Magai, 2008), as in our study different ages correspond to different cohorts, which may have different life and educational experiences (e.g., couple relationships and gender roles in relationships) and different expectations from relationships. Different experiences may affect relationship satisfaction and, consequently, attachment orientations, as well as forms of self-relating, as suggested by the alternative models tested. Further studies should address the role of contextual factors and dyadic effects at different life span and family life cycle points.

A number of limitations must be noted. The primary limitation is the cross-sectional 
design of the study, which does not allow causal inferences to be made or exclusion of alternative models that can also fit the data. In addition, dyadic adjustment is a dynamic process. These aspects could be better understood using a longitudinal design testing a cross-lagged model with multiple assessments of each variable, which would allow us to distinguish uni- and bidirectional effects. Second, there was an imbalance between men and women participating in this study (27\% and $73 \%$, respectively) and in education levels ( $86.6 \%$ of people with graduate level studies or higher). The distribution strategy used may account for the sample imbalance with regard to education levels and the increased socioeconomic level of the sample compared with Portuguese national levels. Third, there was a disproportion in people cohabiting $(73.7 \%)$ with romantic partners. Future studies should address this issue because of the correlation between cohabiting time and attachment dimensions. We must also mention the exclusive use of self-report instruments, which may artificially inflate the association between variables due to shared method variance. Additionally, self-report instruments may not accurately reflect what people actually feel, think or do in real life and may be prone to the social desirability effect. Nevertheless, this effect may have been minimized by the online, anonymous completion of the questionnaires. Finally, in the current study, dyadic functioning may be best conceptualized as "perceived" functioning. Ideally, both members of the couple should be assessed through different methods (e.g. Current Relationship Interview), which would allow dyadic analyses to be conducted.

A number of strengths should be highlighted. To our knowledge, this is the first study that addresses the mediating role of forms of self-criticism in the association between attachment and dyadic adjustment. In addition, this study has important practical 
implications. Intervening in attachment patterns may be particularly challenging because early experiences with primary caregivers are structured in interpersonal schemata that are not easily accessible for intervention and are resistant to change (Fraley \& Shaver, 2000). The identification of more manageable factors linking adult attachment and dyadic functioning is critically important for professionals working with couples wishing to maintain or improve their relationships. One factor that should be evaluated and addressed in couple therapy appears to be inadequate self form of self-criticism. The pathogenic qualities of self-criticism have been linked to an inability to generate feelings of selfwarmth and reassurance, which can counteract the sense of threat associated with selfcriticism (Gilbert \& Procter, 2006). Promoting self-compassion within romantic relationships may increase relationship quality. Self-compassionate individuals present a more positive behaviour in romantic relationships and a higher relationship satisfaction than people lacking self-compassion (Neff \& Beretvas, 2012).

Compassion-focused therapy may be particularly well suited in this context because it aims to promote the activation of the soothing system of affect regulation (Gilbert, 2010), which allows people to experience warmth, safety and connectedness in intimate relationships. However, there is still few evidence of the efficacy of this therapy and, to the best of our knowledge, it has not been applied in the context of couple therapy yet. Other interventions that may be useful in helping couples attain a more self-compassionate stance include the Mindfulness-Based Relationship Enhancement (Carson, Carson, Gil, \& Baucom, 2004) and the Mindful Self-Compassion Program (Neff \& Germer, 2011). Helping people to deal with feelings of inadequacy in a self-compassionate way may contribute to more satisfying, gratifying and fulfilling relationships and should therefore be 
equated in the context of couple therapy.

\section{References}

Amitay, O. A., Mongrain, M., \& Fazaa, N. (2008). Love and control: Self-criticism in parents and daughters and perceptions of relationship partners. Personality and Individual Differences, 44, 75-85. DOI: 10.1016/j.paid.2007.07.020.

Baldwin, M. W. (1992). Relational schemas and the processing of social information. Psychological Bulletin, 112, 461-484.

Baldwin, M. W. (Ed.) (2005). Interpersonal cognition. New York: Guilford Press.

Besser, A., Flett, G. L., \& Davis, R. A. (2003). Self-criticism, dependency, silencing the self, and loneliness: A test of a meditational model. Personality and Individual Differences, 35, 1735-1752. DOI: 10.1016/S0191-8869(02)00403-8

Blatt, S. J. (2004). Experiences of depression: Theoretical, clinical and research perspectives. Washington, DC: American Psychological Association.

Blatt, S. J., \& Homann, E. (1992). Parent-child interaction in the etiology of dependent and self-critical depression. Clinical Psychology Review, 12, 47-91.

Bowlby, J. (1982/1969). Attachment and loss: Vol. 1. Attachment $\left(2^{\text {nd }}\right.$ ed.). New York: Basic Books.

Bowlby, J. (1973). Attachment and loss: Vol. 2. Separation: Anxiety and anger. New York: Basic Books.

Busby, D. M., Christensen, C., Crane, D. R., \& Larson, J. H. (1995). A revision of the dyadic adjustment scale for use with distressed and nondistressed couples: Construct 
hierarchy and multidimensional scales. Journal of Marital and Family Therapy, 21, 289308. DOI: $10.1111 /$ j.1752-0606.1995.tb00163.x

Cantazaro, A., \& Wei, M. (2010). Adult attachment, dependence, self-criticism, and depressive symptoms: A test of a meditational model. Journal of Personality, 78, 11351162. DOI: $10.1111 /$ j.1467-6494.2010.00645.x

Carson, J. W., Carson, K. M., Gil, K. M., \& Baucom, D. H. (2004). Mindfulness-based relationship enhancement. Behavior Therapy, 35, 471-494.

Cassidy, J. (1988). Child-mother attachment and the self in the 6-year-olds. Child Development, 59, 121-134.

Castilho, P., Pinto-Gouveia, J., \& Duarte, J. (2013). Exploring self-criticism: Confirmatory factor analysis of the FSCRS in clinical and nonclinical samples. Clinical Psychology and Psychotherapy, DOI: 10.1002/cpp.1881

Chopik, W. J., Edelstein, R. S., \& Fraley, R. C. (2013). From the craddle to the grave: Age differences in attachment from early adulthood to old age. Journal of Personality, 81, 171-183. DOI: 10.1111/j.1467-6494.2012.00793.x

Cohen, J. (1988). Statistical power analysis for the behavioural sciences. Hillsdale: Erbaum.

Davila, J., Karney, B. R., \& Bradbury, T. N. (1999). Attachment change processes in the early years of marriage. Journal of Personality and Social Psychology, 76, 783-802.

Doyle, A. B., Markiewicz, D., Brendgen, M., Lieberman, M., \& Voss, K. (2000). Child attachment security and self-concept: Associations with mother and father attachment style and marital quality. Merril-Palmer Quaterly, 46, 514-539.

Fraley, R. C., Heffernan, M. E., Vicary, A. M., \& Brumbaugh, C. C. (2011). The 
experiences in close relationships - relationship structures questionnaire: A method for assessing attachment orientations across relationships. Psychological Assessment, 23, 615-625. DOI: $10.1037 / \mathrm{a} 0022898$.

Fraley, R. C., \& Shaver, P. R. (2000). Adult romantic attachment: Theoretical developments, emerging controversies, and unanswered questions. Review of General Psychology, 4, 132-154. DOI: 10.1037/1089-2680.4.2.132.

Fritz, M. S., \& MacKinnon, D. P. (2007). Required sample size to detect the mediated effect. Psychological Science, 18, 233-239.

Gilbert, P. (2000). Social mentalities: Internal "social" conflicts and the role of the inner warmth and compassion in cognitive therapy. In P. Gilbert \& K. G. Bailey (Eds.), Genes on the couch: Explorations in evolutionary psychotherapy (pp. 118-150). Hove: Psychology Press.

Gilbert, P. (2010). Compassion focused therapy. W. Dryden (Ed.). New York: Routledge.

Gilbert, P., Baldwin, M. W., Irons, C., Baccus, J. R., \& Palmer, M. (2006). Self-criticism and self-warmth: An imagery study exploring their relation to depression. Journal of Cognitive Psychotherapy: An International Quarterly, 20, 183-200.

Gilbert, P. Clarke, M., Hempel, S., Miles, J. N. V., \& Irons, C. (2004). Criticizing and reassuring oneself: an exploration of forms, styles and reasons in female students. British Journal of Clinical Psychology, 43, 31-50.

Gilbert, P., \& Irons, C. (2004). A pilot exploration of the use of compassionate images in a group of self-critical people. Memory, 12, 507-516. DOI: 10.1080/096582104444000115

Gilbert, P., McEwan, K., Bellew, R., Mills, A., \& Gale, C. (2009). The dark side of competition: How competitive behaviour and striving to avoid inferiority are linked to 
depression, anxiety, stress and self-harm. Psychology and Psychotherapy: Theory, Research and Practice, 82, 123-136. DOI: 10.1348/147608308X379806

Gilbert, P., \& Procter, S. (2006). Compassionate mind training for people with high shame and self-criticism: Overview and pilot study of a group therapy approach. Clinical Psychology and Psychotherapy, 13, 353-379. DOI: 10.1002/cpp.507.

Gillath, O., Shaver, P. R., \& Mikulincer, M. (2005). An attachment-theoretical approach to compassion and altruism. In P. Gilbert (Ed.), Compassion: Its nature and use in psychotherapy (pp. 121-147). London: Brunner-Routledge.

Gross, C. A., \& Hansen, N. E. (2000). Clarifying the experience of shame: The role of attachment style, gender, and investment in relatedness. Personality and Individual Differences, 28, 897-907. DOI: 10.1016/S0191-8869(99)00148-8

Hazan, C., \& Shaver, P. (1987). Romantic love conceptualized as an attachment process. Journal of Personality and Social Psychology, 52, 511-524.

Hayes, A. F. (2013). Introduction to mediation, moderation, and conditional process analysis: A regression-based approach. New York: Guilford Press.

Irons, C., Gilbert, P., Baldwin, M. W., Baccus, J. R., \& Palmer, M. (2006). Parental recall, attachment relating and self-attacking/self-reassurance: Their relationship with depression. British Journal of Clinical Psychology, 45, 297-308. DOI: $10.1348 / 014466505 \times 68230$

Kopala-Sibley, D. C., Zuroff, D. C., Leybman, M. J., \& Hope, N. (2013). Recalled peer relationship experiences and current levels of self-criticism and self-reassurance. Psychology and Psychotherapy, 86, 33-51. DOI: 10.1111/j.2044-8341.2011.02044.x.

Kopala-Sibley, D. C., \& Zuroff, D. C. (2014). The developmental origins of personality 
vulnerabilities to psychopathology from the self-definition and relatedness domains: A review of theory and research. Review of General Psychology, 18, 137-155. DOI: $10.1037 /$ gpr0000013

Lassri, D., \& Shahar, G. (2012). Self-criticism mediates the link between childhood emotional maltreatment and young adults' romantic relationships. Journal of Social and Clinical Psychology, 31, 289-311.

Laurenceau, J. P., Feldman Barrett, L., \& Pietromonaco, P. R. (1998). Intimacy as an interpersonal process: The importance of self-disclosure, partner disclosure, and perceived partner responsiveness in interpersonal exchanges. Journal of Personality and Social Psychology, 74, 1238-1251.

Lawrence, E., Eldridge, K. A., \& Christensen, A. (1998). The enhancement of traditional behavioural couples therapy: Consideration of individual factors and dyadic development. Clinical Psychology Review, 18, 745-764.

Lopez, J. L., Riggs, S. A., Pollard, S. E., \& Hook, J. N. (2011). Religious commitment, adult attachment, and marital adjustment in newly married couples. Journal of Family Psychology, 25, 301-309. DOI: 10.1037/a0022943

Lowyck, B., Luyten, P., Demyttenaere, K., \& Croveleyn, J. (2008). The role of romantic attachment and self-criticism and dependency for the relationship satisfaction of community adults. Journal of Family Therapy, 30, 78-95.

Luyten, P., \& Blatt, S. J. (2011). Integrating theory-driven and empirically-derived models of personality development and psychopathology: A proposal for DSM V. Clinical Psychology Reviews, 31, 52-68. DOI: 10.1016/j.cpr.2010.09.003

Mackinnon, S. P., Sherry, S. B., Antony, M. M., Stewart, S. H., Sherry, D. L., \& Hartling, 
N. (2012). Caught in a bad romance: perfectionism, conflict and depression in romantic relationships. Journal of Family Psychology, 26, 215-225. DOI: 10.1037/a0027402

Magai, C. (2008). Attachment in middle and later life. In J. Cassidy \& P. R. Shaver (Eds.), Handbook of attachment: Theory, research and clinical applications $\left(2^{\text {nd }}\right.$ ed., pp. 532551). New York: Guilford Press.

Magai, C., Hunziker, J., Mesias, W., \& Culver, L. C. (2000). Adult attachment styles and emotional biases. International Journal of Behavioral Development, 24, 301-309.

McCarthy, G., \& Maughan, B. (2010). Negative childhood experiences and adult love relationships: The role of internal working models of attachment. Attachment and Human Development, 12, 445-461. DOI: 10.1080/14616734.2010.501968

Meyers, S. A., \& Landsberger, S. A. (2002). Direct and indirect pathways between adult attachment style and marital satisfaction. Personal Relationships, 9, 159-172.

Mikulincer, M. (1995). Attachment style and the mental representation of the self. Journal of Personality and Social Psychology, 69, 1203-1215.

Mikulincer, M., \& Goodman, G. S. (2006). Dynamics of romantic love: Attachment, caregiving, and sex. New York: Guildford Press.

Mikulincer, M., \& Shaver, P. R. (2004). Security-based self-representations in adulthood: Contents and processes. In N. S. Rholes, \& J. A. Simpson (Eds), Adult attachment: Theory, research and clinical implications. (pp. 159-195). New York: Guildford.

Mikulincer, M., \& Shaver, P. R. (2008). Adult attachment and affect regulation. In J. Cassidy \& P. R. Shaver (Eds.), Handbook of attachment: Theory, research and clinical applications ( $2^{\text {nd }}$ Ed.; pp. 503-531). New York: Guilford Press.

Moreira, H., Martins, T., Gouveia, M. J., \& Canavarro, M. C. (2014). Assessing adult 
attachment across different contexts: Validation of the Portuguese version of the Experiences in Close Relationships - Relationship Structures Questionnaire. Journal of Personality Assessment. DOI:10.1080/00223891.2014.950377.

Murray, S. L., Bellavia, G. M., Rose, P., \& Griffin, D. W. (2003). Once hurt, twice hurtful: How perceived regard regulates daily marital interactions. Journal of Personality and Social Psychology, 84, 126-147.

Murray, S. L., Holmes, J. G., Griffin, D. W., Bellavia, G., \& Rose, P. (2001). The mismeasure of love: How self-doubt contaminates relationship beliefs. Personality and Social Psychology Bulletin, 27, 423-436. DOI: 10.1177/0146167201274004.

Neff, K. D., \& Beretvas, S. N. (2012). The role of self-compassion in romantic relationships. Self and Identity, DOI: 10.1080/15298868.2011.639548

Neff, K. D., \& Germer, C. (2011). Mindful Self-Compassion Training. Presentation given at the Max Planck Institute, Berlin, Germany.

Overall, N. C., \& Fletcher, G. J. O. (2010). Perceiving regulation from intimate partners: Reflected appraisal and self-regulation processes in close relationships. Personal Relationships, 17, 433-456. DOI: 10.1111/j.1475-6811.2010.01286.x

Saavedra, M. C., Chapman, K. E. \& Rogge, R. D. (2010). Clarifying links between attachment and relationship quality: Hostile conflict and mindfulness moderators. Journal of Family Psychology, 24, 380-390. DOI: 10.1037/a0019872

Santor, D. A., Pringle, J. D., \& Israeli, A. L. (2000). Enhancing and disruptive cooperative behavior in couples: Effects of dependency and self-criticism following favorable and unfavorable performance feedback. Cognitive Therapy and Research, 24, 379-397.

Santor, D. A., \& Zuroff, D. C. (1998). Controlling shared resources: Effects of dependency, 
self-criticism, and threats to self-worth. Personality and Individual Differences, 24, 237252.

Shahar, G., Joiner Jr., T. E., Zuroff, D. C., \& Blatt, S. J. (2004). Personality, interpersonal behavior, and depression: co-existence of stress-specific moderating and mediating effects. Personality and Individual Differences, 36, 1583-1596. DOI: 10.1016/j.paid.2003.06.006

Smolewska, K., \& Dion, K. L. (2005). Narcissism and adult attachment: A multivariate approach. Self and Identity, 4, 59-68.

Sturman, E. D., \& Mongrain, M. (2008). The role of personality in defeat: A revised social rank model. European Journal of Personality, 22, 55-79. DOI: 10.1002/per.653

Tabachnick, B. G., \& Fidell, L. S. (2007). Using multivariate statistics (5th ed.). Boston, MA: Pearson Education, Inc.

Thompson, R. A. (2008). Early attachment and later development. In J. Cassidy \& P. R. Shaver (Eds.), Handbook of attachment: Theory, research and clinical applications $\left(2^{\text {nd }}\right.$ Ed.; pp. 348-365). New York: Guilford Press.

Thompson, R., \& Zuroff, D. C. (1999). Development of self-criticism in adolescent girls: Roles of maternal dissatisfaction, maternal coldness and insecure attachment. Journal of Youth and Adolescence, 28, 197-210.

Weinfield, N. S., Sroufe, L. A., Egeland, B., \& Carlson, E. (2008). Individual differences in infant-caregiver attachment: Conceptual and empirical aspects of security. In J. Cassidy \& P. R. Shaver (Eds.), Handbook of attachment: Theory, research and clinical applications (2 ${ }^{\text {nd }}$ Ed.; pp. 78-101). New York: Guilford Press.

Wiseman, H., Mayseless, O., \& Sharabany, R. (2006). Why are they lonely? Perceived 
quality of early relationships with parents, attachment, personality predispositions and loneliness in first-year university students. Personality and Individual Differences, 40, 237-248. DOI: 10.1016/j.paid.2005.05.015

Zhang, F., \& Labouvie-Vief, G. (2004). Stability and fluctuation in adult attachment style over a 6-year period. Attachment and Human Development, 6, 419-437.

Zuroff, D. C., \& Duncan, N. (1999). Self-criticism and conflict resolution in romantic couples. Canadian Journal of Behavioural Science, 31, 137-149. DOI: 10.1037/h0087082.

Zuroff, D. C., \& Fitzpatrick, D. K. (1995). Depressive personality styles: Implications for adult attachment. Personality and Individual Differences, 18, 253-265.

Zuroff, D. C., \& Mongrain, M. (1987). Dependency and self-criticism: Vulnerability factors for depressive affective states. Journal of Abnormal Psychology, 96, 14-22.

BLIND FOR REVIEW. Psychometric properties of the Revised Dyadic Adjustment Scale (RDAS) in a community sample of couples (submitted for publication). 


\section{Figure Captions}

Figure 1. Statistical diagram of the parallel multiple mediator model for the presumed influence of self-criticism and self-reassurance on the effects of global attachment anxiety and avoidance on dyadic adjustment. Path values represent standardised regression coefficients. In the arrows linking attachment dimensions and dyadic adjustment, the values outside the parentheses represent the total effect of attachment anxiety or avoidance on dyadic adjustment before the inclusion of the mediating variables. The values in parentheses represent the direct effect, from the bootstrapping analysis, of attachment anxiety or avoidance on dyadic adjustment after inclusion of the mediators. ${ }^{*} p<.05 ; * * p<$ $.01 ; * * p<.001$ 
Table 1

Socio-demographic characteristics of the sample

$N=230$

Mean (SD); observed range

Age (years)

$33.76(9.95) ; 18-66$

Relationship time (months)

119.09 (110.17); 6-588

Cohabiting time (months)

75.58 (105.80); 0-519

$n(\%)$

Gender

Male

$62(27)$

Female

$168(73)$

\section{Cohabitation status}

Cohabiting

$170(73.9)$

Non-cohabiting

$60(26.1)$

\section{Education levels}

Undergraduate studies

$30(13)$

Graduate studies

$111(48.3)$

Post-graduate studies

$88(38.3)$

Missing information

$1(0.4)$

\section{Professional status}

Employed

$165(71.7)$ 
Unemployed

Retired

Student

Other

Household income (per month)

$<800 €$

$800-2000 €$

$2000-3500 €$

$>3500 €$

Missing information
$25(10.9)$

7 (3)

$22(9.6)$

$11(4.8)$
$16(7)$

$107(46.5)$

$75(32.6)$

$27(11.7)$

$5(2.2)$ 
Table 2

Descriptive statistics and correlations among study variables

\begin{tabular}{|c|c|c|c|c|c|c|c|}
\hline \multicolumn{2}{|c|}{ Variables } & & 1 & 2 & 3 & 4 & 5 \\
\hline \multirow[t]{2}{*}{1} & Attachment avoidance & $2.32(0.73)$ & - & & & & \\
\hline & & $1-4.75$ & & & & & \\
\hline \multirow[t]{2}{*}{2} & Attachment anxiety & $2.19(1.20)$ & $.39 * *$ & - & & & \\
\hline & & $1-6.33$ & & & & & \\
\hline \multirow[t]{2}{*}{3} & Dyadic adjustment & $50.22(7.94)$ & $-.27 * *$ & $-.27 * *$ & - & & \\
\hline & & $18-66$ & & & & & \\
\hline \multirow[t]{2}{*}{4} & Inadequate Self & $12.89(7.12)$ & $.29 * *$ & $.29 * *$ & $-.38 * *$ & - & \\
\hline & & $0-36$ & & & & & \\
\hline \multirow[t]{2}{*}{5} & Hated Self & $2.02(2.55)$ & $.34 * *$ & $.36^{* *}$ & $-.27 * *$ & $.62 * *$ & - \\
\hline & & $0-16$ & & & & & \\
\hline \multirow[t]{2}{*}{6} & Reassured Self & $21.78(5.86)$ & $-.46 * *$ & $-.25 * *$ & $.29 * *$ & $-.47 * *$ & $-.54 * *$ \\
\hline & & $2-32$ & & & & & \\
\hline
\end{tabular}


Table 3

Indirect effect of attachment dimensions on self-criticism and self-reassurance through dyadic adjustment

\begin{tabular}{lccc}
\hline & $a b$ & $S E$ & $95 \% \mathrm{BCaCI}$ \\
\hline Inadequate Self & .056 & .025 & {$[.02 ; .12]$} \\
Anxiety & .060 & .025 & {$[.02 ; .12]$} \\
Avoidance & & & \\
\hline Hated Self & .029 & .022 & {$[.00 ; .09]$} \\
Anxiety & .031 & .024 & {$[.02 ; .10]$} \\
Avoidance & & & \\
\hline Reassured Self & & .019 & {$[-.08 ;-.00]$} \\
Anxiety & -.033 & .022 & {$[-.09 ;-.00]$} \\
Avoidance & -.035 & & \\
\hline
\end{tabular}




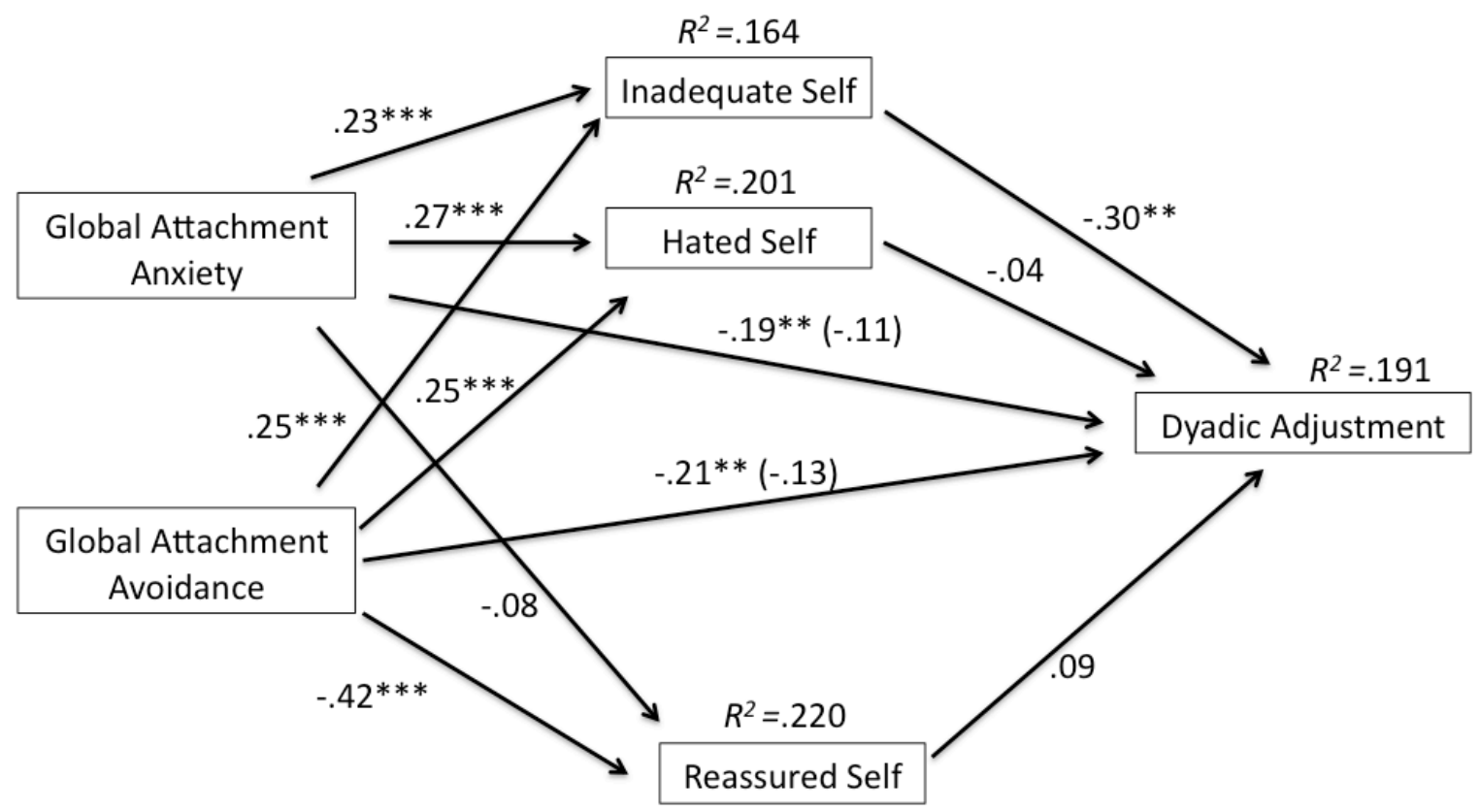

Figure 1 